\title{
Optimization Performance of Irreversible Refrigerators Based on Evolutionary Algorithm
}

\section{Mohammad H. Ahmadi ${ }^{1, *}$, Mohammad Ali Ahmadi ${ }^{2}$ and Milad Ashouri ${ }^{1}$}

1 Department of Renewable Energies, Faculty of New Science and Technologies, University of Tehran, Tehran, Iran; E-Mails: mohammadhosein.ahmadi@gmail.com; ashouri.milad@ut.ac.ir

2 Department of Petroleum Engineering, Ahwaz Faculty of Petroleum Engineering, Petroleum University of Technology (PUT), Ahwaz, Iran, Address; E-Mails: ahmadi6776@yahoo.com Author to whom correspondence should be addressed; E-Mail: mohammadhosein.ahmadi@gmail.com; Tel.: +989122866205.

Received: 14 September 2014 / Accepted: 14 September 2014 / Published: 3 November 2014

\begin{abstract}
In early works done by authors, performance analysis of refrigeration systems such as power input, refrigeration load and coefficient of performance (COP) was investigated. In this article a new function called "Coefficient of Performance Exergy" or COPE has been introduced. Two objective functions of coefficient of performance exergy and exergy destruction are optimized simultaneously using the multi-objective optimization algorithm NSGAII. COPE has been maximized and exergy destruction has been minimized in order to get the best performance. Decision making has been done by means of two methods of LINAMP and TOPSIS. Finally an error analysis done for optimized values shows that LINAMP method is preferable against TOPSIS method.
\end{abstract}

Keywords: refrigeration; coefficient of performance; exergy destruction; Decision making

\section{Introduction}

Numerous researches performed in finite-time thermodynamics where the coefficient of performance (COP) is selected as the objective function in the optimization analysis [1 - 4]. Performance optimization of the heat engines had been studied since 1996 by selection of the power density as the objective function [5 -7] which is able to optimize the cycle performance containing the effects of the engine size. Similar study accomplished for the Ericsson [8] and Stirling [9] refrigeration cycles in 
which both the internal and external losses were neglected and the cooling load density was utilized as the optimization objective. Recently, significant strides have been made in the research and development for Brayton refrigeration cycles [10].

Numerous studies have been done since the 1970 s for refrigerators to classify the performance restrictions and to optimize the thermodynamic cycles [11-22]. Most of the above mentioned work have chosen the input power, cooling load, exergy output rate, COP and entropy generation rate as the optimization objectives. An ecological objective function for finite-time Carnot heat engines was first introduced by Angulo-Brown et al. [23] as $E^{\prime}=P-T_{L} S$ in which $T_{L}$ stands for the of the cold heat source temperature, $P$ is the output power and $\sigma$ represents the rate of entropy generation. Yan [24] improved this objective to $E=P-T_{0} S$ where $T_{0}$ is the ambient temperature.

Solving multi-objective optimization problems is too difficult because the resulting different objective functions should be satisfied simultaneously while they may even conflict. Evolutionary algorithms (EA) were the first techniques developed and utilized during the mid-eighties which enabled solving problems of such generic class stochastically [25]. When such a method is to be used, a multi-objective problem gives rise to an assortment of optimum answers, each of the objective functions is satisfied at an acceptable level where the other solutions are not being dominated [26]. In general, multi-objective optimization show a countless assortment of possible answers called Pareto frontier, whose assessed vectors in the objective function space symbolize the greatest possible trade-offs. Nowadays, multiobjective optimization of various systems in energy and thermodynamics engineering is generating interest in many researchers throughout the world [27-34].

In the current work a irreversible refrigerators were optimized using evolutionaryalgorithm while coefficient of performance of exergy, the rate of exergy destruction are presumed as objectives of the optimization, while thermal operating variables of refrigerator including the Internal irreversibility parameter $(\phi)$, the internal conductance of the refrigerator $(C)$, working fluid in the cycle works at temperature $T_{L C}$ and heat transfer surface area ratio $(t)$ are considered as decision variables.

\section{Model and Basic Assumption}

Figure (1) illustrates the Temperature-Entropy $(T-S)$ schematics diagram for an irreversible refrigerator. The temperatures of the heat source and heat sink where the cycle operates are represented by $T_{H}$ and $T_{L}$, correspondingly. The working fluid throughout the cycle operates at temperature $T_{L C}$ and $T_{H C}$, correspondingly. The temperature gradient $\left(T_{H C}-T_{H}\right)$ throughout the high-temperature heat exchanger creates $Q_{H C}$ while $Q_{L C}$ is made because to the driving force of $\left(T_{L}-T_{L C}\right)$. $Q_{L}$ denotes 
the net heat transfer rate from the heat sink, viz., the cooling load $(R)$ and $Q_{H}$ stands for the net heat transfer rate to the heat source. The correlation between $T_{H}, T_{H C}, T_{L C}, T_{L}$ should satisfy the below expression

$T_{H C}>T_{H}>T_{L}>T_{L C}$

Figure 2 depicts a model used in the current paper for a universal irreversible refrigerator and its surrounds.

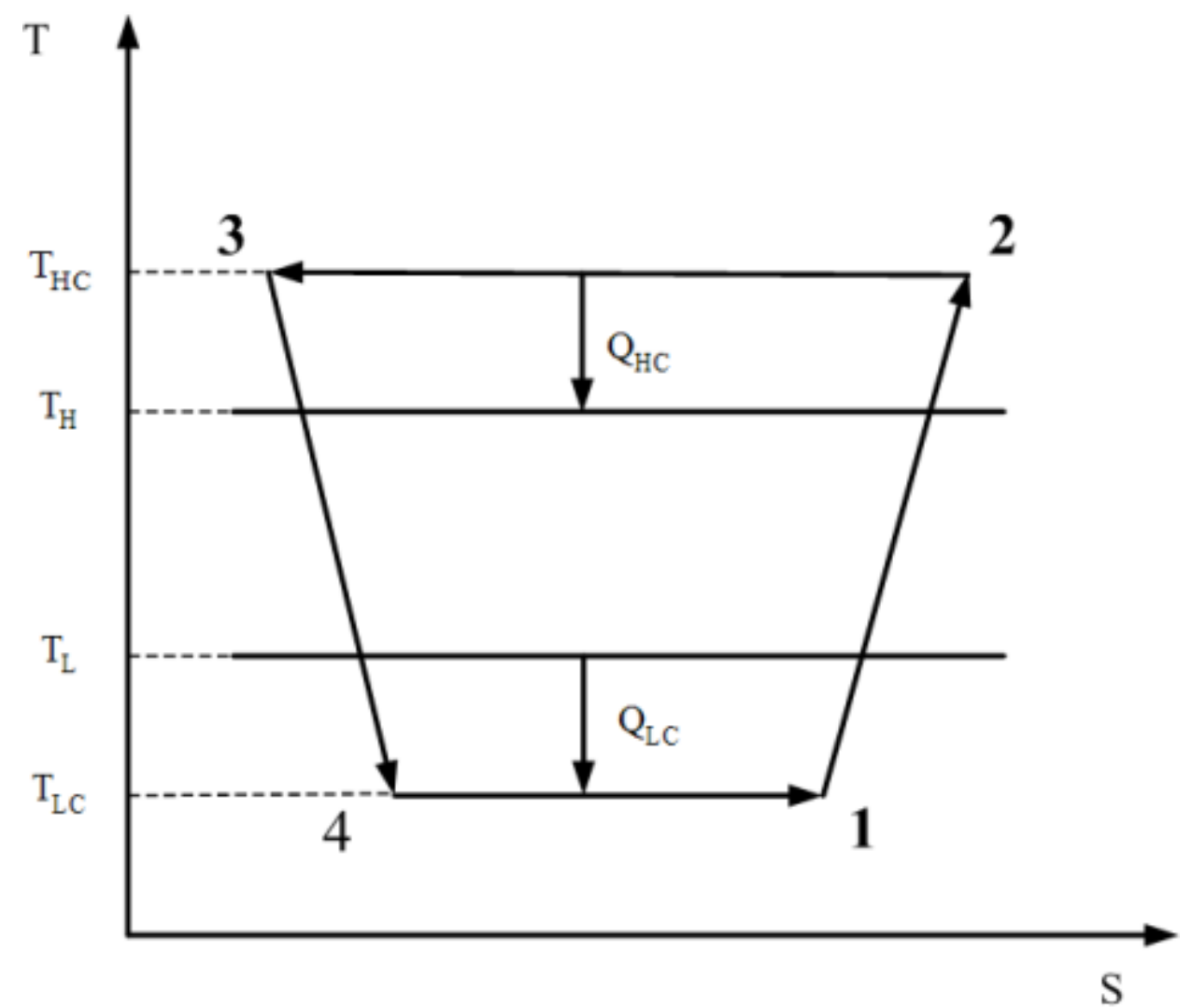

Figure 1. $T-S$ diagram for the generalized refrigerator model. 


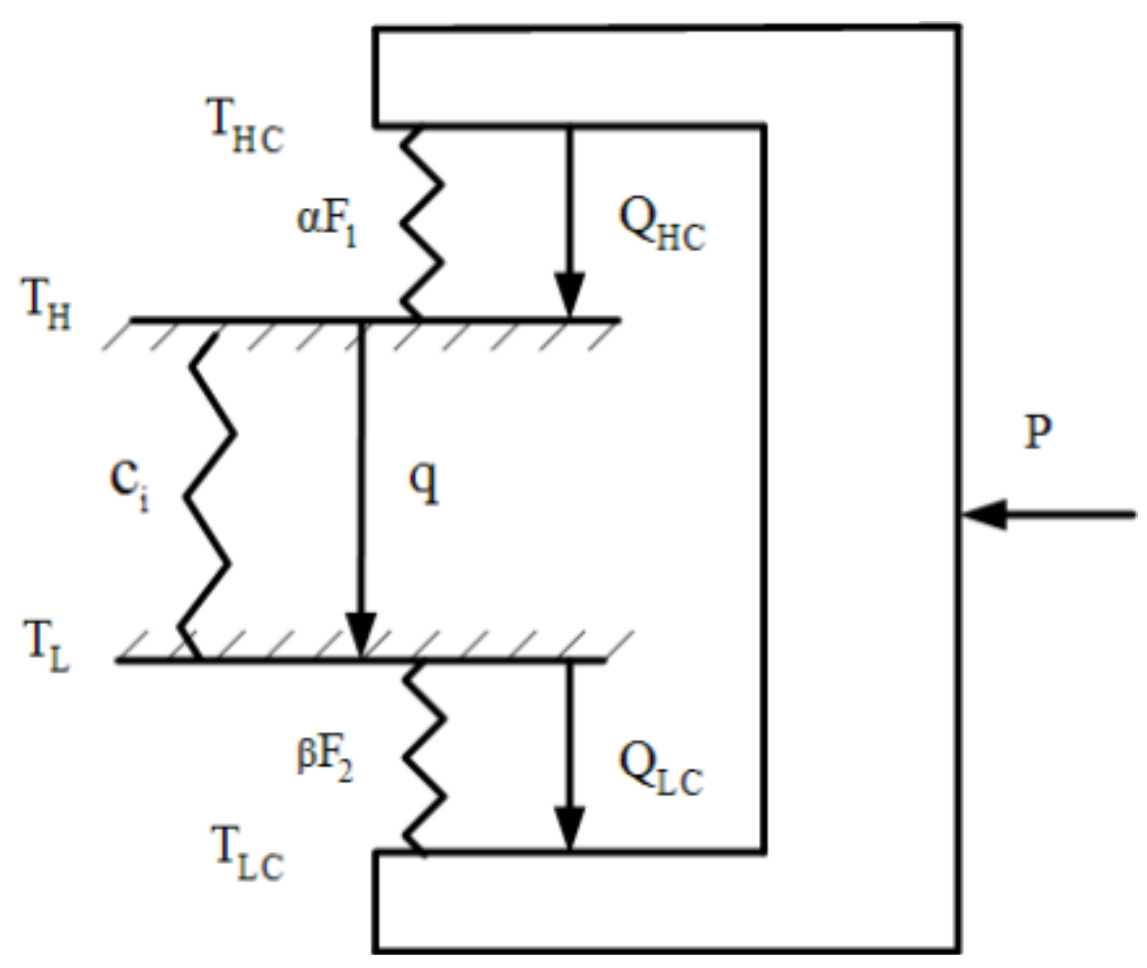

Figure 2. The model of the generalized refrigerator and its surroundings.

The model is based on some assumptions as follows:

(1) The steady state fluid flow is assumed for the working fluid and the cycle comprises of four irreversible processes including two adiabatic and two isothermal.

(2) The low-and high- temperature heat exchangers have finite heat transfer surface areas denoted by $F_{2}$ and $F_{1}$, respectively while the overall heat transfer surface area $(F)$ for the two aforementioned heat exchangers is presumed to be consistent:

$F=F_{1}+F_{2}$

(3) Due to the existence of heat leakage $(q)$ from the heat sink to the heat source, it is obtained that:

$Q_{H}=Q_{H C}-q$

$Q_{L}=R=Q_{L C}-q$

$q=C\left(T_{H}-T_{L}\right)$

(4) The irreversibilities throughout the cycle take place owing to: (i) thermal resistivity between the working fluid and the heat resources. (ii) heat loss among the heat resources and (iii) various parameters such as instability, friction and non-equilibrium accomplishments in the bounds of the 
refrigerator. Consequently, more power is required as input associated to an endoreversible refrigerator. The heat rejection rate to the heat sink $\left(Q_{H C}\right)$ of a universal irreversible refrigerator is much more than an endoreversible one $\left(Q_{H C}^{\prime}\right)$. These irreversibilities can be scaled by introducing a constant factor, $\phi$, which characterizes the extra internal varied irreversibility influence:

$\phi=\frac{Q_{H C}}{Q_{H C}^{\prime}} \geq 1$

Compared to the endoreversible [35] and irreversible [36-39] refrigerator approaches, the developed model is more general and reliable. If $q=0$ and $\phi=1$, the approach would be summary to the endoreversible refrigerator [35] while for $q>0$ and $\phi=1$, the approach is summary to an irreversible refrigerator with heat leak losses and heat resistance [36]. For $q=0$ and $\phi>1$, the approach is summary to the irreversible refrigerator with internal irreversibilities and heat resistance [36-39].

For an irreversible refrigerator, the second law of thermodynamics needs that:

$\frac{Q_{H C}^{\prime}}{Q_{L C}}=\frac{T_{H C}}{T_{L C}}$

Merging formulas (6) and (7) provides:

$\frac{Q_{H C}}{Q_{L C}}=\phi\left(\frac{T_{H C}}{T_{L C}}\right)$

Presume that the heat transfers among the refrigerator and its surrounds obey Newton's linear law:

$Q_{H C}=\alpha F_{1}\left(T_{H C}-T_{H}\right)$

$Q_{L C}=\beta F_{2}\left(T_{L}-T_{L C}\right)$

Moreover, following formula defines a heat transfer surface area ratio $(f)$ :

$$
f=\frac{F_{1}}{F_{2}}
$$

According to the first law of thermodynamics, The power input $(P)$ to the refrigerator can be determined via following equation:

$P=Q_{H C}-Q_{L C}=Q_{H}-Q_{L}=Q_{H}-R$

The coefficient of performance $(C O P)$ of the refrigerator is:

$C O P=\frac{Q_{L}}{P}=\frac{R}{P}$

Equations (7)-(13) provide: 
$C O P=\frac{R}{(R+q)\left(\phi \frac{T_{H C}}{T_{L C}}-1\right)}$

$S=\frac{Q_{H}}{T_{H}}-\frac{Q_{L}}{T_{L}}$

Merging Equations (8)-(11) gives:

$\frac{Q_{H C}}{R+q}=\phi \frac{T_{H C}}{T_{L C}}=\frac{f \alpha\left(T_{H C}-T_{H}\right)}{\beta\left(T_{L}-T_{L C}\right)}$

which then yields:

$\frac{T_{H C}}{T_{L C}}=\frac{T_{H}(f \alpha / \beta)}{(\phi+f \alpha / \beta) T_{L C}-\phi T_{L}}$

Merging Equations (2) and (9)-(11) provides:

$T_{L C}=T_{L}-\frac{(R+q)(1+f)}{\beta F}$

Replacing formula (18) into formulas (16) and (17), then following equations can be obtained:

$$
\begin{gathered}
\frac{T_{H C}}{T_{L C}}=\frac{T_{H}(f \alpha / \beta)}{(\phi+f \alpha / \beta)\left(T_{L}-\frac{(R+q)(1+f)}{\beta F}\right)-\phi T_{L}} \\
Q_{H C}=\frac{T_{H} \phi(R+q)}{\left(\frac{\phi}{\alpha}+\frac{f}{\beta}\right)} \\
T_{L}-(R+q)(1+f) \frac{\alpha F}{f F}
\end{gathered}
$$

To derive the entropy generation rate $(S)$ and coefficient of performance $(C O P)$ of the generalized irreversible refrigerator cycle, we substitute the Equations (19) and (20) into Equations (14) and (15) as following as:

$$
S=\frac{\phi(R+q)}{T_{L}-(R+q)(1+f) \frac{\left(\frac{\phi}{\alpha}+\frac{f}{\beta}\right)}{f F}}-\frac{R}{T_{L}}-\frac{q}{T_{H}}
$$


$C O P=\left[\frac{R}{R+q}\right]\left\{\frac{\phi T_{H}}{\left[T_{L}-(R+q)(1+f) \frac{\left(\frac{\phi}{\alpha}+\frac{f}{\beta}\right)}{f F}\right]-1}\right\}^{-1}$

From exergy analysis point of view, the objective function of ecological optimization, suggested by Angulo-Brown [23] and improved by Yan [24], can be obtain via following equation:

$E=P-T_{0} S$

In which $T_{0}$ denotes the temperature of environment.

The ecological coefficient of performance $(E C O P)$ was proposed by Ust and colleagues [22], as the proportion of power output to the loss rate of availability, i.e.,

$$
E C O P=\frac{P}{T_{0} S}
$$

From exergy analysis point of view, Chen and colleagues [40] present an ecological optimization objective for refrigerator cycles as following as:

$\dot{I}=T_{0} S$

$E=R\left[\left(\frac{T_{0}}{T_{L}}-1\right)-\left(1+\frac{1}{C O P}\right)\left(\frac{T_{0}}{T_{H}}-1\right)\right]-T_{0} S$

The coefficient of performance of exergy $(C O P E)$ is proposed as the proportion of exergy loss rate (entropy generation rate) and the exergy output rate, consequently, COPE is a dimensionless ecological function and it can be written as following equation as:

$C O P E=\frac{R\left[\left(\frac{T_{0}}{T_{L}}-1\right)-\left(1+\frac{1}{C O P}\right)\left(\frac{T_{0}}{T_{H}}-1\right)\right]}{T_{0} S}$

\section{Multi-objective optimization with evolutionary algorithms}

\subsection{Optimization via EA}

Using genetic algorithm (GA) which is classified under evolutionary algorithms, we obtained Pareto frontier. John Holland was the first who suggested and developed genetics algorithm in the 1960s which integrate natural adaptation approach with computer algorithms and numerical optimization techniques [25.26].A computer simulation is used for optimization problem and generation of acceptable solution where a population of abstract demonstrations named chromosomes of nominee answers named individuals evolves. The random 
population of generated individuals is the start point of the evolution and the generation process repeats. In each step, the evaluation of every individual fitness is performed and multiple individuals are selected randomly from the current population (according to their fitness).Then, they modified (feasibly randomly mutated and recombined) and finally a new population is generated. Each generated population is needed to be used for the next step of the algorithm. Algorithm dismisses when either the number of generations reaches its maximum, or the population reaches its satisfactory fitness level. In the second case, an acceptable solution cannot be achieved. The term chromosome refers to a candidate solution of a genetics algorithm problem, and the fitness function gives the evolutionary feasibility of each chromosome. The technique is an effective way to solve nonlinear problems $[25,26]$. In addition, the complexity of classical techniques can be reduced by multiobjective evolutionary algorithms (MOEAs) which have recently been advanced by using many different tests on complex engineering and mathematical issues $[25,26]$. Schematics of the present study MOEA is showed in Fig. 3 [28-33]. Instead of using binary codes, the actual values of decision parameters are considered.

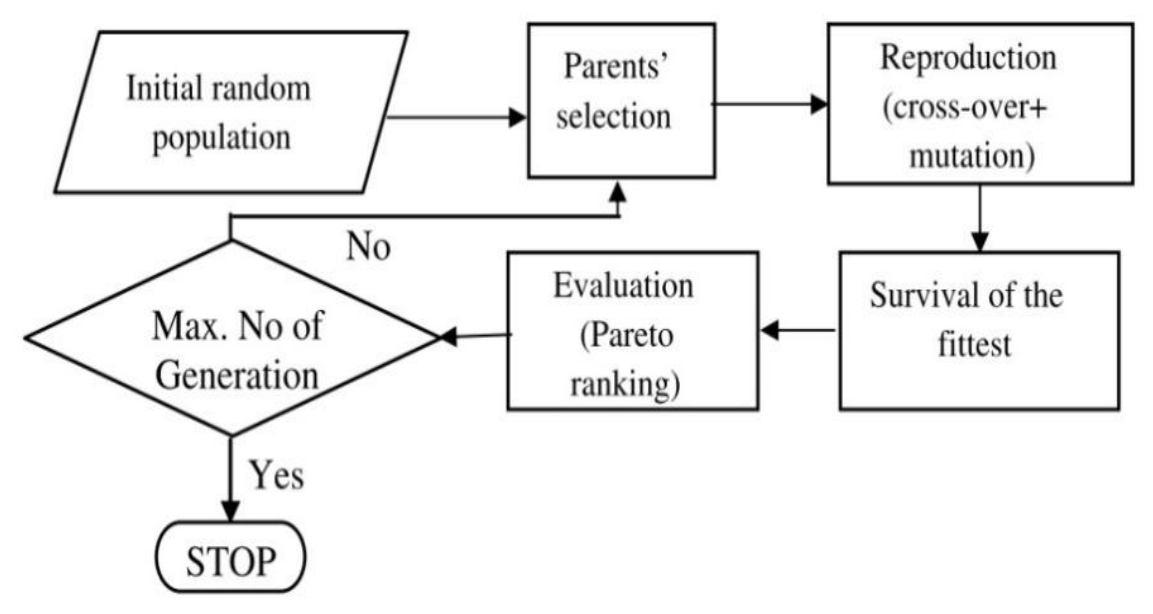

Figure.3.Scheme for the multi-objective evolutionary algorithm used in the present study [28-33].

\subsection{Objective functions, decision parameters and limitations}

Two important objective functions for optimization are the exergy destruction (should be minimized), the coefficient of performance of exergy (should be maximized) represented by Eq.(24) and Eq.(26), correspondingly.

Throughout this research, four decision parameters are presumed as following as:

$\phi$ : Internal irreversibility parameter

$C$ : The internal conductance of the refrigerator

$t:$ The heat transfer surface area ratio 
$T_{L C}$ : Working fluid temperature (K)

The objective functions in regard to below limitations are unraveled:

$0.01 \leq C \leq 0.03(\mathrm{~kW} / \mathrm{K})$

$1 \leq \phi \leq 1.3$

$0.5 \leq f \leq 4$

$240 \leq T_{L C} \leq 255$

\subsection{Decision-making in the multi-objective optimization}

After optimization process with multi variables and objectives, selecting an ultimate optimum outcome from the results gained by evolutionary approach has a great importance. Thanks to this fact, numerous methods that known as decision making techniques can be execute to determine desire optimal variables from the frontier of Pareto that is previously gained. Throughout this research, two robust, high performance and well-known decision maker techniques including LINMAP and TOPSIS approaches are utilized. Ultimate optimum outcomes were determined on the basis of the expert knowledge and indexes through results that proposed with the aim of decision maker approaches. Extensive description of two decision makers can be found in following references [28-33].

\section{Result an discussion}

The coefficient of performance of exergy (COPE) is maximized simultaneously and the exergy destruction $\left(T_{0} S\right)$ is minimized concurrently employing the multi-objective optimizing approach which operates according to the NSGA-II method.

By the way, optimization is accomplished via objective functions that are formulated by Eqs. (25) and (27) limitations which are represented via Eqs. (28)-(31).

With the intention of have reliability with earlier publications, descriptions of the Irreversible refrigerator cycle are presumed as following as [41],

$T_{H}=300 \mathrm{~K}, T_{L}=260 \mathrm{~K}, T_{0}=290 \mathrm{~K}$

Pareto optimal frontier exhibited in Fig.4 Also, obtained optimum solutions of LINMAP and TOPSIS methods exhibited in Fig.4. From Fig.4 it can be seen that optimal solution of COPE varied of 3.3 to 3.5 and optimal solution of $T_{0} S$ varied of 0.17 to 0.24 . 


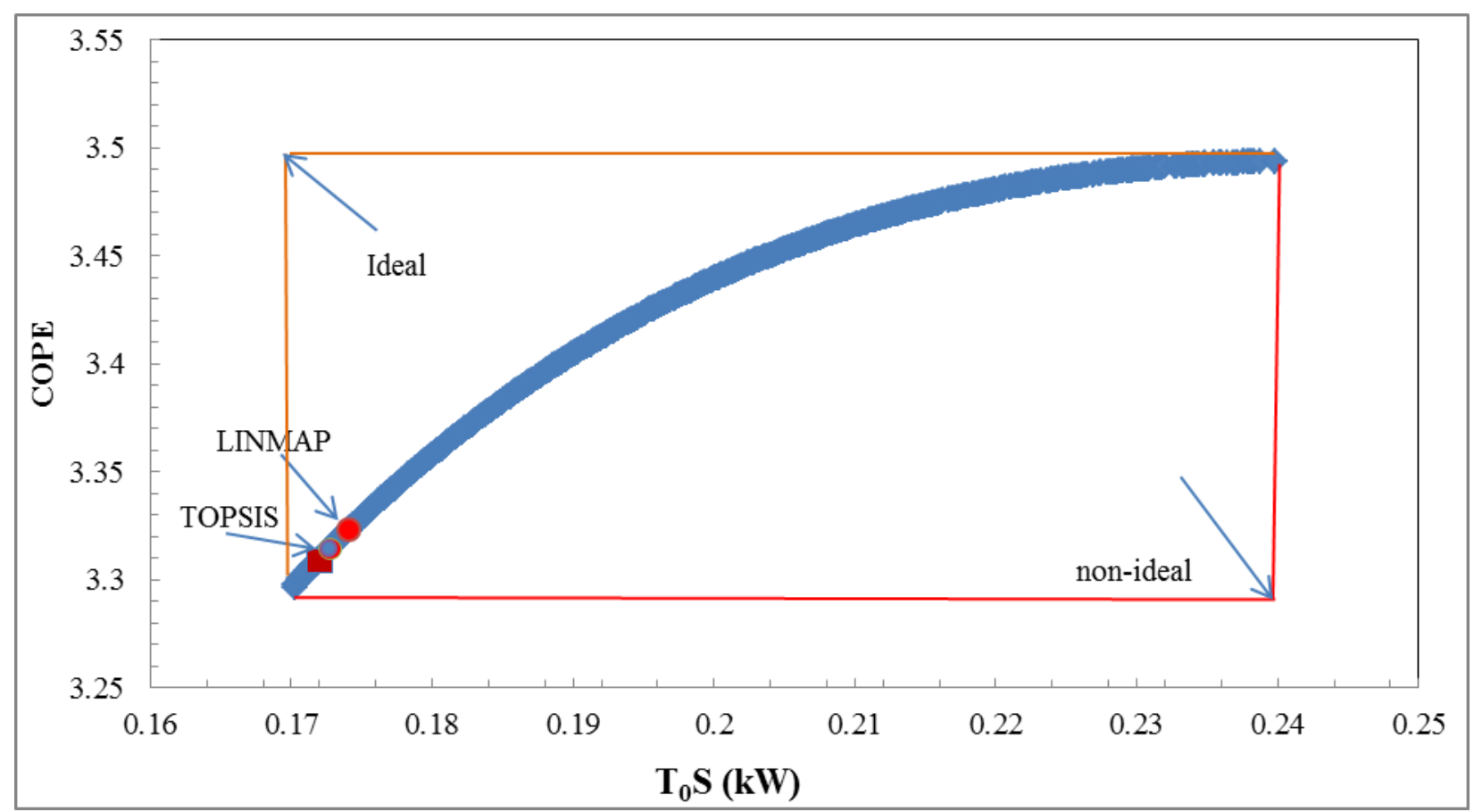

Figure.4. Pareto frontier (Pareto optimal solutions) for $T_{0} S$ versus COPE using NSGA-II.

Figs 5 to 8 are exhibited the distribution of different values of decision parameter in their permissible rang for the optimum design points on the Pareto front. It can be seen from Fig.5 that distribution of $C$ in $C=0.01$ was marked by blue line and $C$ obtained lower value. From Fig. 6 it can be seen that distribution of $\phi$ in $\phi=1$ was marked by blue line and $\phi$ obtained lower value. From Fig.7 it can be seen that distribution of various values of $f$ which the range of 2.48 to 4 was further. It can be seen from Fig.8 that distribution of $T_{L C}$ in $T_{L C}=255 \mathrm{~K}$ was marked by blue line and $T_{L C}$ obtained higher value.

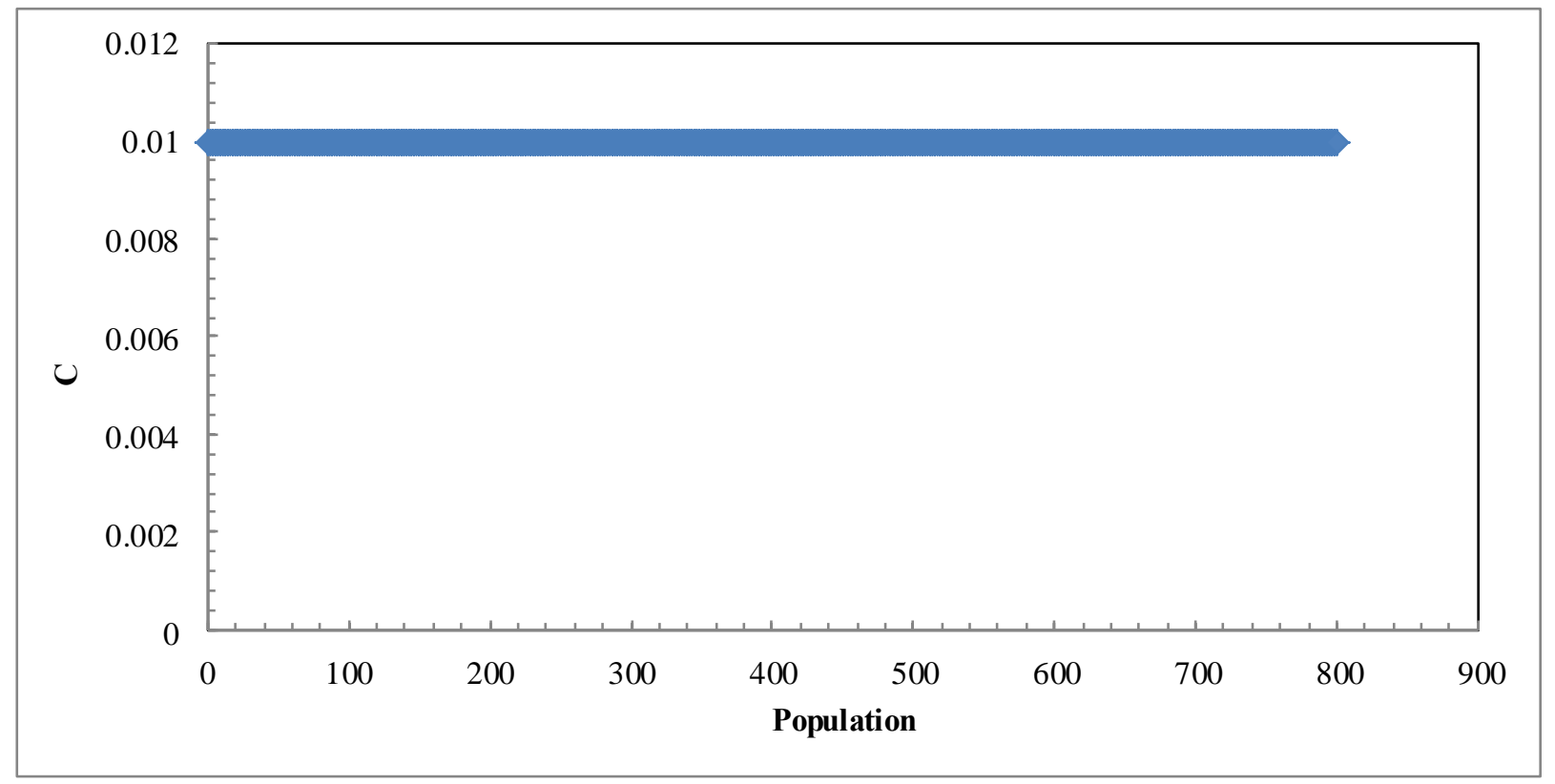

Figure.5.The distribution of $C$ for the optimal points on Pareto front. 


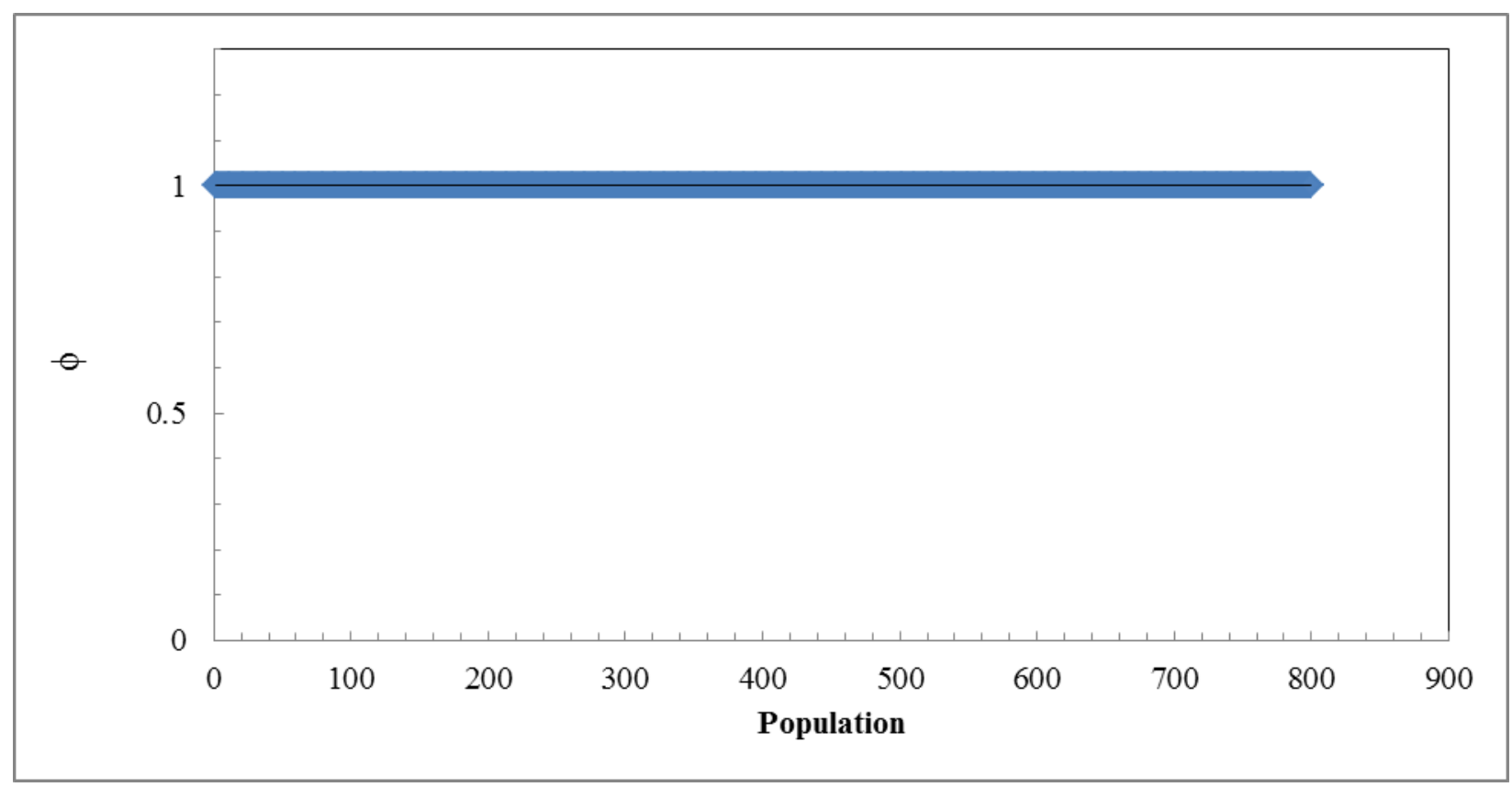

Figure.6.The distribution of $\phi$ for the optimal points on Pareto front.

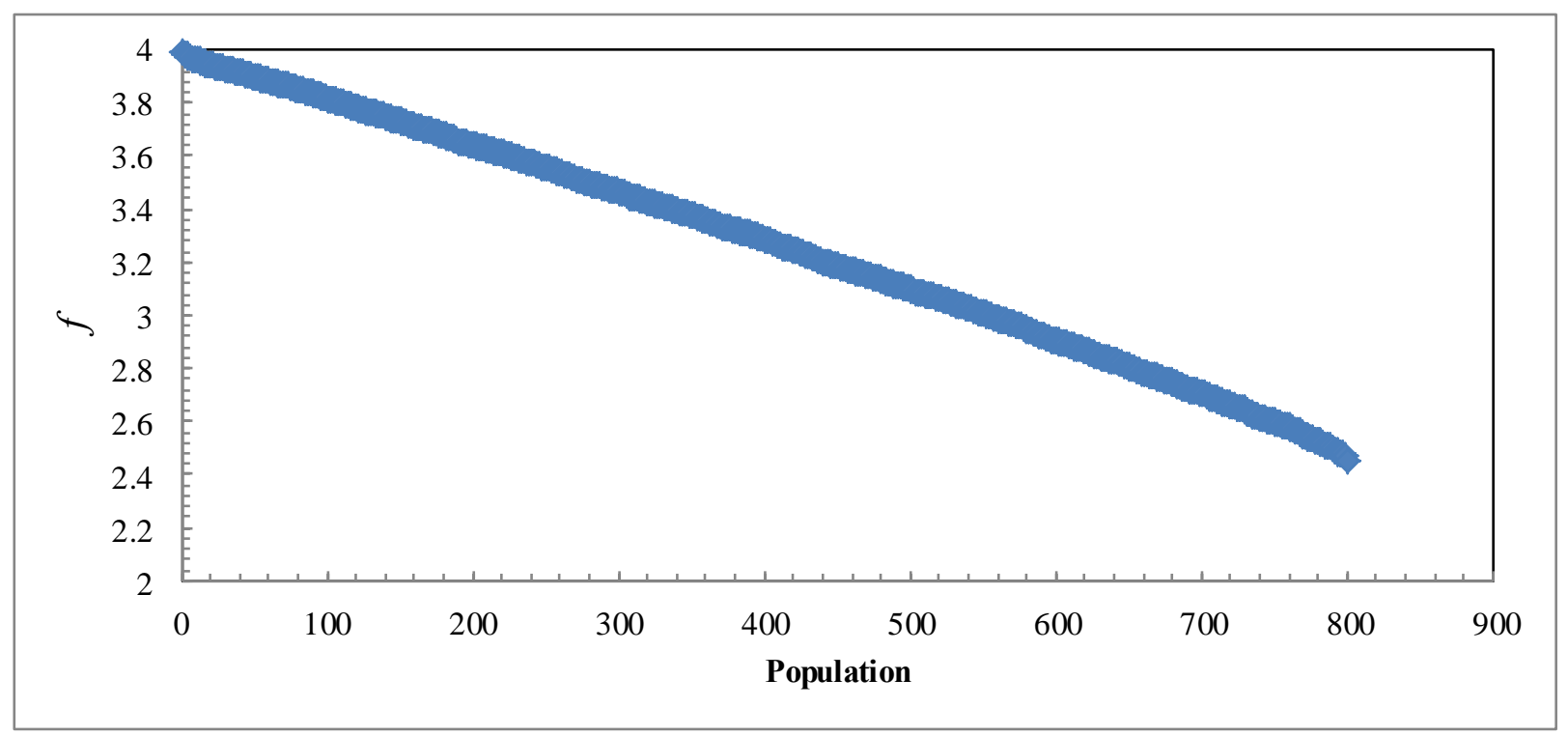

Figure.7.The distribution of $f$ for the optimal points on Pareto front. 


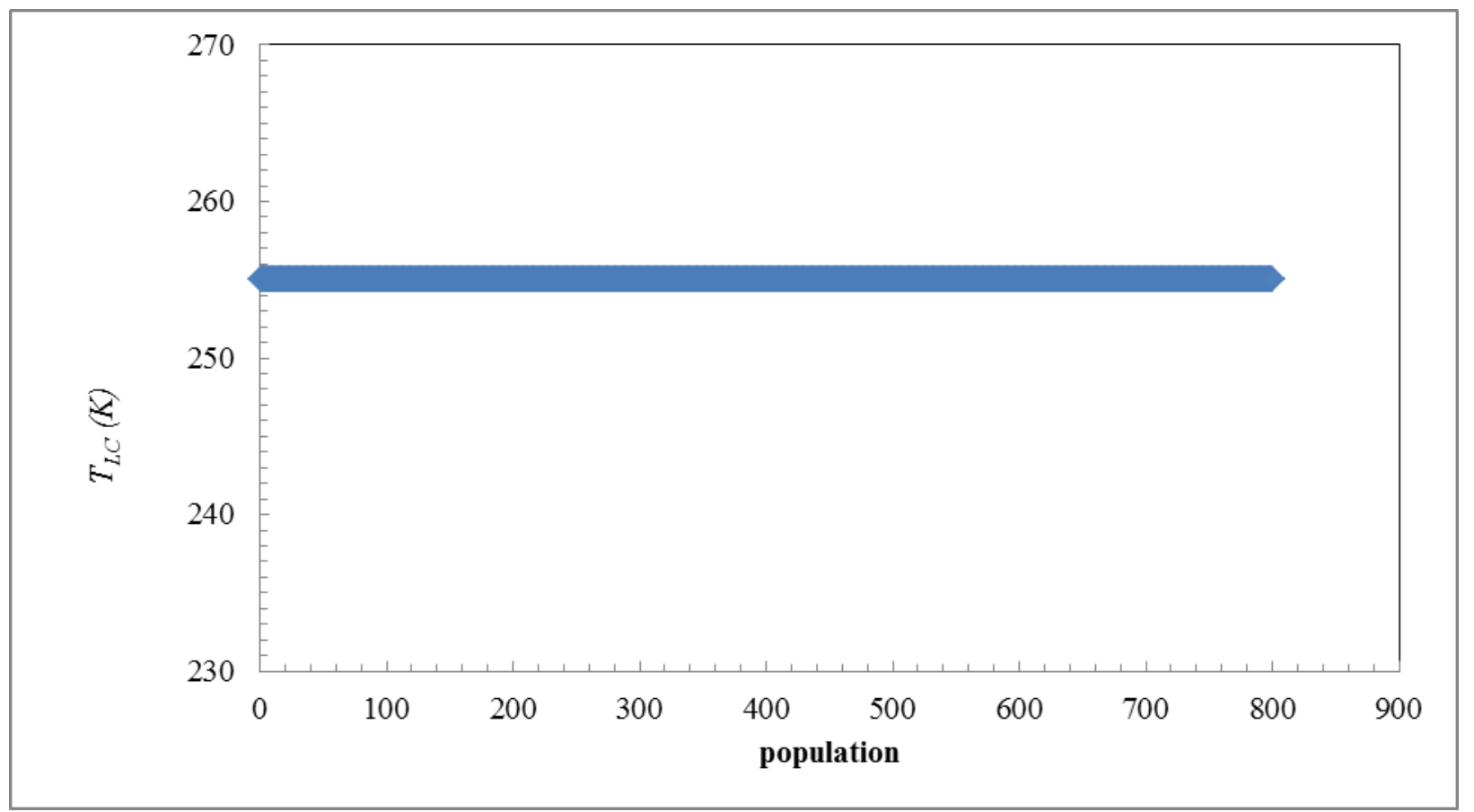

Figure.8.The distribution of $\phi$ for the optimal points on Pareto front.

Table 1 report optimum solutions gained throughout this research employing two decision making approaches.

Table 1: Decision making of multi-objective optimal solutions.

\begin{tabular}{|l|c|c|c|c|c|c|}
\hline \multirow{2}{*}{ Decision Making Method } & \multicolumn{4}{|l|}{ Decision variables } & \multicolumn{2}{l|}{ Objective functions } \\
\cline { 2 - 7 } & $C$ & $\phi$ & $f$ & $T_{L C}$ & $T_{0} S$ & \multirow{2}{*}{ COPE } \\
\hline TOPSIS & & & & & & 3.3142 \\
\hline LINMAP & 0.01 & 1.000013 & 3.90 & 255 & 0.17272 & 3.3232 \\
\hline
\end{tabular}

\subsection{Error Analysis:}

For error analysis, the mean absolute percentage error (MAPE) is employed. For this goal, 30 runs of each method are accomplished to provide ultimate outcome. First and second row of Table 2 shows maximum absolute percentage error (MAAE) and (MAPE) respectively.

Table2: Error analysis based on the mean absolute percent error (MAPE) method.

\begin{tabular}{|l|c|c|c|c|}
\hline Decision Making Method & \multicolumn{2}{|l|}{ TOPSIS } & \multicolumn{2}{l|}{ LINMAP } \\
\hline Objectives & $C O P E$ & $T_{0} S$ & $C O P E$ & $T_{0} S$ \\
\hline Max Error \% & 4.13 & 14.86 & 3.88 & 15.04 \\
\hline Average Error \% & 1.74 & 5.43 & 1.64 & 5.41 \\
\hline
\end{tabular}

\section{Conclusions}


In this study, thermodynamic analysis has been applied to determine the exergy destruction and the coefficient of performance of exergy ( $C O P E)$ of the refrigerator. The exergy destruction and the $C O P E$ of the refrigerator are presumed concurrently for multi-objective optimization the Internal irreversibility parameter $(\phi)$, the internal conductance of the refrigerator $(C)$, heat transfer surface area ratio $(t)$ and working fluid in the cycle operates at temperature $T_{L C}$ are presumed as design variables. Multi objective evolutionary approach is presumed according to the NSGA-II method and the Pareto optimal frontier throughout objectives space is acquired. An ultimate optimum answer is nominated from answers of the Pareto frontier employing two decision making approaches comprising TOPSIS and LINMAP techniques.

\section{Conflicts of Interest}

The authors declare no conflict of interest.

\section{References and Notes}

1. A. Bejan, Entropy Generation Minimization, CRC Press, Boca Raton FL, 1996.

2. R. S. Berry, V.A. Kazakov, S. Sieniutycz, Z. Szwast, and A. M. Tsirlin, Thermodynamic Optimization of Finite Time Processes, Wiley, Chichester, 1999.

3. L. Chen, C.Wu, and F. Sun, Finite time thermodynamics optimization or entropy generation minimization of energy systems, J. Non-Equilibrium Thermodyn. 24, 327 (1999).

4. C. $\mathrm{Wu}, \mathrm{L}$. Chen, and J. Chen, (eds.), Recent Advances in Finite Time Thermodynamics, Nova Science Publishers, New York, 1999.

5. B. Sahin, A. Kodal, and H. Yavuz, Maximum power density analysis of an endoreversible Carnot heat engine, Energy, The Int. 21, 1219 (1996).

6. L. Berrin, A. Sisman, and H. Yavuz, Analysis of Ericsson cycle at maximum power density conditions, ECOS 1996, pp. 25-27.

7. L. Chen, J. Lin, F. Sun, and C. Wu, Efficiency of an Atkinson engine at maximum power density, Energy Convers. Mgmt. 39, 337 (1998).

8. H. L. Yavuz and L.B. Erbay, General performance characteristics of an Ericsson refrigerator, ECOS 1998, Nancy, France, pp. 565-571.

9. L.B. Erbayan d H. Yavuz, The maximum cooling density of a realistic Stirling refrigerator, J. Phys. D: Appl. Phys. 31, 291 (1998).

10. J.A. Mc Cormick, Progress on the development of miniature turbo-machines for low capacity reverse Brayton cryocooler, Proc. 9-th Int. Cryocooler Conf., 1996.

11. Chen, L.G.; Wu, C.; Sun, F.R. Finite time thermodynamic optimization or entropy generation minimization of energy system. J. Non-Equil. Thermodyn. 2005, 24, 327-359.

12. Chen, L.G.; Zhang, L.; Sun, F.R. Power, efficiency, entropy-generation rate and ecological 
Optimization for a class of generalized irreversible universal heat-engine cycles. Appl. Energy 2007, 84, 512-525.

13. Durmayaz, A.; Sogut, O.S.; Sahin, B.; Yavuz, H. Optimization of thermal systems based on finite-time thermodynamics and thermoeconomics. Prog. Energy Combust. Sci. 2004, 30, 175-217.

14. Chen, C.K.; Su, Y.F.; Exergetic efficiency optimization for an irreversible Brayton refrigeration cycle. Int. J. Therm. Sci. 2005, 44, 303-310.

15. Tu, Y.; Chen, L.G.; Sun, F.R.; Wu, C. Cooling load and efficient of performance optimizations for real air-refrigerators. Appl. Energy 2006, 83, 1289-1306.

16. Zhu, X.Q.; Chen, L.G.; Sun, F.R.; Wu, C. Effect of heat transfer law on the ecological optimization of a generalized irreversible Carnot heat pump. Int. J. Exergy 2005, 2, 423-436.

17. Chen, L.G.; Zhu, X.Q.; Sun, F.R.; Wu, C. Ecological optimization of a generalized irreversible Carnot refrigerator for a generalized heat transfer law. Int. J. Ambient Energy 2007, 28, 213-219.

18. Zhu, X.Q.; Chen, L.G.; Sun, F.R.; Wu, C. Exergy based ecological optimization for a generalized irreversible Carnot refrigerator. J. Energy Inst. 2006, 79, 42-46.

19. Chen, L.G.; Li, J.; Sun, F.R. Generalized irreversible heat-engine experiencing a complex heattransfer law. Appl. Energy 2008, 85, 52-60.

20. Chen, J.; Chen, X.; Wu, C. Optimisation of rate of exergy output of a multistage endoreversible combined refrigeration system. Exergy 2001, 1, 100-106.

21. Morosuk, T.; Tsatsaronis, G. Advanced exergetic evaluation of refrigeration machines using different working fluids. Energy 2009, 34, 2248-2258.

22. Ust, Y. Performance analysis and optimization of irreversible air refrigeration cycles based on ecological coefficient of performance criterion. Appl. Therm. Eng. 2009, 29, 47-55.

23. Angulo-Brown, F. An ecological optimization criterion for finite-time heat engines. J. Appl. Phys. 1991, 69, 7465-7469.

24. Yan, Z. Comment on "ecological optimization criterion for finite-time heat-engines". J. Appl. Phys. 1993, 73, 3583.

25. Veldhuizen, D.A.V., Lamont, G.B., Multi-objective Evolutionary Algorithms: Analyzing the State-of-the-Art, Evolutionary Computation, 8(2000), pp.125-147

26. Konak, A., Coit, D.W., Smith, A.E., Multi-objective optimization using genetic algorithms: A tutorial, Reliability Engineering \&amp, System Safety, 91(2006), pp. 992-1007

27. Bck, T., Fogel, D., Michalewicz, Z., Handbook of evolutionary computation, Oxford Univ. Press, 1997

28. Ahmadi MH, Hosseinzade H, Sayyaadi H, Mohammadi AH, Kimiaghalam F. Application of the multi-objective optimization method for designing a powered Stirling heat engine: design with maximized power, thermal efficiency and minimized pressure loss. Renew Energy 2013;60:31322.

29. Ahmadi MH, Sayyaadi H, Mohammadi AH, Marco A. Barranco-Jimenez. Thermo-economic multi-objective optimization of solar dish-Stirling engine by implementing evolutionary algorithm, Energy Conversion and Management, 73 (2013), pp. 370-380 
30. Ahmadi MH., Ahmadi MA., Mohammadi AH. , Mehrpooya M., Feidt M., Thermodynamic optimization of Stirling heat pump based on multiple criteria, Energy Conversion and Management 80, 319-328 (2014)

31. Lazzaretto, A., Toffolo, A., Energy, economy and environment as objectives in multi-criterion optimization of thermal systems design, Energy, 29(2004), pp. 1139-1157

32. Mohammad H. Ahmadi, Mohammad Ali Ahmadi, Amir H. Mohammadi, Michel Feidt, Seyed Mohsen Pourkiaei . Multi-objective optimization of an irreversible Stirling cryogenic refrigerator cycle, Energy Conversion and Management 82 (2014) 351-360

33. Ahmadi MH, Mohammadi AH, S Dehghani. Evaluation of the maximized power of a regenerative endoreversible Stirling cycle using the thermodynamic analysis, Energy Conversion and Management 76 (2013), pp. 561-570

34. Toghyani S., Kasaeian A., Ahmadi MH., Multi-objective optimization of Stirling engine using non-ideal adiabatic method. Energy Conversion and Management 80, 54-62 (2014).

35. Chen, L.G.; Sun, F.R.; Wu, C. Ecological optimization criteria for an endoreversible Carnot refrigerator. Nat. J. 1992, 15, No. 8, (in Chinese).

36. Gordon, J.M.; Ng, K.C. Thermodynamic modeling of reciprocating chillers. J. Appl. Phys. 1994, 75, 2769-2774.

37. Sun, F.R.; Wu, C.; Chen, L.G. Optimal performance and rate of entropy production for forward and reverse irreversible Carnot cycles. Chin. J. Eng. Thermophys. 1991, 12, 357-360.

38. Ait-Ali, M.M. A class of internally irreversible refrigeration cycles. J. Phys. D 1996, 29, 593599.

39. Ait-Ali, M.M. The maximum coefficient of performance of internally irreversible refrigerators and heat pumps. J. Phys. D 1996, 29, 975-980.

40. Chen, L.G.; Zhu, X.; Sun, F.R.; Wu, C. Ecological optimization for generalized irreversible Carnot refrigerators. J. Phys. D 2005, 35, 113-118.

41. Xu, J.; Pang, L.; Wang, J. Performance Optimization of Generalized Irreversible Refrigerator Based on a New Ecological Criterion. Entropy 2013, 15, 5277-5291.

(C) 2014 by the authors; licensee MDPI, Basel, Switzerland. This article is an open access article distributed under the terms and conditions of the Creative Commons Attribution license (http://creativecommons.org/licenses/by/3.0/). 